\title{
BEYOND THE BOW: \\ A DIGITAL SOLUTION FOR THE QUEER COMMUNITY
}

by

\author{
Katarina A. Zlatanovic \\ Bachelor of Science in the Honours Program \\ Environmental \& Resource Science \\ Sustainable Agriculture \& Food Systems.,
}

Trent University, 2018

\begin{abstract}
A Major Research Paper
presented to Ryerson University
\end{abstract}

\begin{abstract}
in partial fulfillment of the
requirements for the degree of

Master of Digital Media

in the Program of Digital Media
\end{abstract}

Toronto, Ontario, Canada, 2019

Toronto, Ontario, Canada, 2019 (C) Katarina A. Zlatanovic, 2019 


\section{AUTHOR'S DECLARATION FOR ELECTRONIC SUBMISSION OF A MRP}

I hereby declare that I am the sole author of this MRP. This is a true copy of the MRP, including any required final revisions.

I authorize Ryerson University to lend this MRP to other institutions or individuals for the purpose of scholarly research.

I further authorize Ryerson University to reproduce this MRP by photocopying or by other means, in total or in part, at the request of other institutions or individuals for the purpose of scholarly research.

I understand that my MRP may be made electronically available to the public.

Katarina A. Zlatanovic 


\begin{abstract}
BEYOND THE BOW:

A DIGITAL SOLUTION FOR THE QUEER COMMUNITY
\end{abstract}

\author{
Master of Digital Media, 2019 \\ Katarina A. Zlatanovic \\ Master of Digital Media, Ryerson University
}

Beyond the Bow is an app for the LGBTQ+ community which will allow users to find queer events in their areas, get involved, circulate information, and help foster and build physical queer spaces in the GTA. Connection of strangers and self-organization of the queer community is what allows for the growth of queer spaces in society and sustains the physical queer geography of cities. Development of this app will cultivate and expand public discourse and support member activity in our community, which is necessary to ensure the prosperity and maintenance of our public. This digital solution is informed by research conducted through participant observation, autoethnography, and discourse analysis. The work is grounded in queer theory. Beyond the Bow will allow for communication in a new, modernized way within the LGBTQ+ community, and help reshape our culture by creating and maintaining real-life connections and queer geography through mediated communication and virtual community-building tools. The overall goal of Beyond the Bow is to offer users an accessible virtual place, that will work as a gateway into our physical queer spaces by providing resources and information surrounding on-going activities and initiatives, thus enhancing member participation and promoting the success of our community. 


\section{Acknowledgments}

I would first like to thank my incredible supervisors, Dr. Alya Naumova and Dr. Paul Moore, who have offered me constant guidance, feedback, and advice throughout the process of researching and writing this paper. Without their dedication, this project and the incredible experience I have gained would not have been possible. I would also like to thank the assistance and support of my incredible MDM 6.0 classmates who inspired me to tackle new projects throughout this year. Finally I would like to thank my partner Meagan, my friend and co-founder of Beyond the Bow Chanel, and my parents and siblings for their constant support.

I would like to dedicate my work to my Baba Jelena.

"You are my inspiration" 


\section{Table of Contents}

Author's Declaration $\quad$ ii

Abstract iii

Acknowledgements

Table of Contents $\quad$ v

$\begin{array}{ll}\text { 1. Introduction } & 1\end{array}$

2. Literature Review $\quad 3$

2.1 The Queer Public 3

2.2 Circulation of Discourse as a Culture-building Tool 4

2.3 Queering Spaces 6

3. Methodology 9

3.1 Participant Observation 10

3.2 Pop Culture Discourse Analysis 11

3.3 Autoethnography 12

$\begin{array}{lr}\text { 4. Results } & 15\end{array}$

$\begin{array}{lr}\text { 5. Landscape Analysis } & 25\end{array}$

6. Synthesis/Analysis $\quad 26$

$\begin{array}{ll}6.1 \text { Next Steps } & 28\end{array}$

$\begin{array}{lr}\text { Appendix } & \mathbf{3 0}\end{array}$

$\begin{array}{ll}\text { References } & 32\end{array}$ 


\section{Introduction}

Queer individuals have historically been suppressed by society, excluded from common spaces, and shamed for who they are. Even in the year 2019, queer Canadians are still facing forms of hate and suppression. Canadian queer folk may have access to some LGBTQ+ safe spaces, either virtual or physical, but such spaces can be considered very inaccessible to some due to location, age-restrictions, and other factors. These queer spaces allow for a circulation of queer discourse, promotion of selfexpression and community-building, and the normalization of queer culture in public spaces.

Queering social spaces is the movement to deconstruct those historically hegemonic views (Hillock and Mulé, 2017). From a personal perspective and experience, LGBTQ+ individuals feel safest among those who identify closest to them. When spaces are queer, we do not have to worry about being misgendered, harassed, assaulted, or even killed for being who we are by those who identify alongside us. When it comes to accessibility of information for those in the community, a lot of queer culture is still kept away from the public eye, even in a country which legalized same-sex marriage over a decade ago. Because so much of our culture is still in the closet, so are our community members.

Social acceptance of LGBTQ+ culture still has a long way to go, so we must be fostering the participation of its members in this culture, circulating queer information in an efficient and widely accessible way, and giving opportunity for development of new physical and virtual safe spaces. To understand the importance of queer spaces and how to foster the growth of our community, we have to understand the function of the counterpublic, how discourse is circulated, and at the very core, what makes a space queer (Warner, 2002). Stepping forward to cultivate and meet the needs of our community, I hope to create a vessel which would circulate information and help to build those physical queer spaces in society. My hope is for members to have the chance to be open and immerse themselves within our queer culture, surrounded by others who love and support them. This stranger sociability would be possible thanks to the discourse created and distributed within the social entity I plan to develop.

I see Beyond the Bow as an extension of our public social space and a step toward modernizing how we access and circulate discourse within our community. This privately accessed gateway to information and resources in our community will bridge the gap between the virtual and the 
physical, and allow for connections to be made among members who otherwise are not able to do so. Making queer connections and friendships has traditionally been a difficult task, especially for those members in the community who are not publicly out yet. By creating this safe online space for users to meet queer friends and connect with others, we are helping them access the wonderful support network that is within our public.

In this paper I will unpack how our queer community communicates and shares information, what it means to queer spaces, and provide a deeper understanding of some problems the LGBTQ + community is facing. I will explain my research methodology used to identify these problems and how such approaches will inform a strong design strategy for Beyond the Bow. I will discuss my findings and provide insight into the queer community and LGBTQ+ culture to demonstrate the need for such a solution, and propose initial design suggestions that can tackle the problems identified. 


\section{$\underline{\text { 2. Literature Review }}$}

\subsection{The Queer Public}

The queer counterpublic is the foundation of the queer movement and our culture. As Warner stated, "A public is the social space created by the reflexive circulation of discourse", and the counterpublic represents groups which wish to re-shape themselves as a public that contests the dominant public's norms (Warner, 2002). Our very existence alone was, and is, a friction against the dominant heteronormative public (Butler, 1993). With our underground roots, came the beginning of our community. As people gathered in created spaces, began distributing and creating channels for information among our members, and started a public where members could participate, a LGBTQ+ community was born. One of the fundamental flaws of this model however, is the inaccessibility to members of the community who may not be in a position to completely immerse themselves in our public. As Michael Warner (2002) had said in his analysis Publics and Counterpublics, "Within a gay or queer counterpublic, for example, no one is in the closet" (Warner, 2002). As mentioned earlier, there are many people who consider themselves LGBTQ+, but may not be in a position to live as themselves openly, and this is due to the friction our community causes against the "traditional" heteronormative society. The forced or presumed outing associated with participating in our queer spaces is one of the largest barriers to members taking an active role in the community. It makes access to our culture, our health resources, and more, physically inaccessible to people who are in this position.

To continue discussing the importance of addressing and finding solutions to such barriers, it is most important to know that the existence of publics are contingent upon member activity and uptake (Warner, 2002). In order for our community to grow and thrive, we must make sure it is accessible to all members, and give opportunity for participation in our culture. Beyond the Bow creates a solution by offering members of our community facing issues of inaccessibility, an opportunity to learn and participate anywhere, whenever they want. Often times, this inaccessibility not only comes from the inability to participate, but the lack of accessible information and the way in which it is circulated. As mentioned, our queer counterpublic was founded and partially still exists as an underground, closeted 
scene. Information and discourse are circulated within that scene which makes member activity so crucial. Should members not be able to access this information and discourse due to inability to participate, they are not only unable to attend and take part in queer gatherings, they have not even heard of most of them in the first place. Our physical queer spaces, and our public overall are dependent on user participation, thus they are reliant on the spread of information among queer members and a digital tool can assist in this manner. A tool which can help create and maintain our spaces and public.

Beyond the Bow's main initiative is to assist with the circulation of information, and promote the resources available to members of our community regardless of their physical location. It can be a privately accessed gateway to information and resources in our community. Such a solution not only offers incredible benefits for the individuals accessing them, but the queer community overall. I see Beyond the Bow as an extension of our public social space. A step towards modernization of how we access and circulate discourse within our community. Beyond the Bow can act as a gateway bridging the gap between the virtual and physical spheres in which our public participates and exists. Connecting these spheres can help connect the public as a whole by circulating discourse among our members, promoting participation in our events and social spaces, and encouraging the growth of both virtual and physical spaces. Beyond the Bow is a solution that has the goals and values of ensuring the success of the queer public.

\subsection{Circulation of Discourse as a Culture-building Tool}

On the topic of information distribution, we need to look at how queer information and resources are currently accessed and circulated by members of the community, and how we can make this more accessible, efficient, and safe. Communication is the basis of all discourse circulation, so I turned to the Cultural Approach to Communication by James Carey (1989) to first understand the importance of sharing information, as well as how various models of communication impact a public and shape how we interact with one another. One of the most defining insights from the book is the following, "Communication is directed toward the maintenance of society in time; the representation of shared beliefs" (Carey, 1989). As a queer community, the way we have traditionally distributed information with 
each other was within our own establishments, throughout our queer-specific social groups, and was communicated in a way that aimed to maintain the well-being of our public. By communicating through channels known to be queer, such as being posted in our queer establishments, only shared via person-toperson, or by queer specific media, our community has been able to ensure the utmost safety of our members. By communicating in a manner that is keeping discourse strictly within our public, we aim to prevent any unsafe circumstances from coming to, or existing within our spaces.

This model for information distribution lacks accessibility and often does not reach the full intended audience. We can understand why information is shared this way, once again looking to our underground roots, but with the recent boom of technology, the queer community now has the capability of sharing information through virtual gateways which can reach much further within our community. Warner had even discussed how any discourse meant to address a public is meant to undergo circulation (Warner, 2002). Our current communication model is one which undergoes limited circulation, where mass media tools are not utilized and our discourse does not reach the entirety of the community. Personto-person communication would never reach the entire community and runs the risk of said information being lost in translation along the way. As stated, it is easy to understand why the queer community has been slow to adapt to new methods of communication, because within our public we run the risk of targeted hate, homophobic protests, and worse. We need a unique model of communication built specifically for the queer community. One which allows LGBTQ+ people to feel safe, welcomed, and is easily accessible by all queer members regardless of physical location.

Carey mentioned that models of communication are not just representations of communication, but also representations for communication which guide concrete processes of human interaction (Carey, 1989). How we interact with each other within the community, shapes the community as a whole. Through such communication, publics have the potential to create and distribute culture and give meaning to spaces. With safer, more accessible and efficient communication amongst our members, we have the ability to reshape our community, not only in a way that can offer more events and more spaces to the entirety of our public, but in a way which normalizes the existence of queer identities in society. Moving forward in the technological age, we have the ability to mass distribute information within our public and reach our community members wherever they are. This is the modernization our 
community needs to ensure the growth and prosperity of our spaces and people. Through a virtual avenue such as Beyond the Bow, people would have access to community events, resources, and general information on a single convenient platform. As Carey said, "Society is possible because of the binding forces of shared information circulating in an organic system" (Carey, 1989). Beyond the Bow as a new model of communication adheres to Carey's ideas in which we are creating a way to rebuild the model of, and for communication, and offer restorative value in reshaping the community's common culture. Dewey (as cited in Cary, 1989) proclaimed, "Communication is "the most wonderful" because it is the basis of human fellowship".

\subsection{Queering Spaces}

After discussing how we share information, and how our community organizes, we can better understand and distinguish how a space is considered queer, and what specifically makes it queer. In understanding what makes a space queer, and how it is possible to even queer a space, we must first understand how they exist otherwise. I look to Judith Butler (1988) and her foundational queer theory surrounding gender and the heterosexual matrix, where straight identity and norms are presumed. Here, we can begin the conversation of what a space fundamentally is in our current societal structure. We understand our current societal model is a combination of pre-existing cultural relations, which are not radical or original in nature. Butler explains that the acts which one does, or one performs, is in some sense, acts which have been taking place prior to one's arrival on the scene (Butler, 1988). This is considered the cultural "norm". A radical act of deviance, contesting such existence, through expressions of differing gender and sexual identities is how we are able to queer spaces.

Introducing queerness and incorporating queer culture, identity, and life into spaces, both virtual and physical, is how we queer a space. How we share our culture, our information, and utilize our models of communication determines how we queer spaces. Re-addressing Carey's idea surrounding communication as a a representation of shared beliefs, by introducing our queer culture in non-queer spaces and communicating our queerness throughout society, we are maintaining our queer public, while

also normalizing our existence in the face of the "norm". We are not simply contesting society's normal, 
we are reshaping it to be inclusive, diverse, and welcoming to all identities. This is what it means to queer.

Explaining this idea further, we have to look at the gender binary construction of our society coming from a phallocentric, patriarchal ideology, when men's experience and bodies are central and normative. In Gender Trouble, Butler (1990) identifies "sex" as a mark applied by institutionalized heterosexuality (Butler, 1990). The importance of this discussion is acknowledging this institutionalized origin of forced heterosexuality and gender binary within our current societal structure, but further knowing that these marks can be erased or obscured through practices that challenge the said institution (Butler, 1990). These practices are those acts of queering social spaces, the movement to deconstruct those historically hegemonic views I mentioned earlier.

Having defined what it means to queer a space, the question remains, how do we do it? What can we specifically do to include queer spaces within society? There are several suggestions I would offer, looking at simple adjustments that make spaces more inclusive, to completely making a space for a specific demographic of people. Small acts of queering spaces could include gender neutral washrooms. Making a clear statement that all people, regardless of gender identity, have access to the same washroom breaks down the traditional gender binary system which has existed for generations. On larger scales, a business may offer events, or set days throughout the year which are specific to certain queer identities. This could include a LGBTQ+ event at a nightclub which is generally non-queer. Still, it can be made known there is a zero tolerance for homophobia, transphobia, or hate of any kind. This is how we introduce the concept and culture of queerness to new spaces. Creating queer spaces and environments which contest the traditional heterosexual matrix and gender binary, are how we create safe spaces for our community and normalize our presence in society. We are here, we are queer, and we too have a space in society. Becoming an inclusive society starts with inclusive businesses, inclusive community centers, and diversity throughout all.

Creating queer spaces and the act of queering in itself is an aim to become inclusionary. Our community exists because of the spaces we have created where we are able to communicate, share our culture with others, and feel welcome and at home. Queering is the act of making space for our community and our culture. Whether those are physical spaces, the language we choose to use, such as 
being conscious of preferred pronouns, the way we communicate and educate, like including queer authors and research within educational curriculum, or even simply acknowledging there are different identities and allowing them to have representation in media, these are some of the mechanisms we can use to queer. There is space for queering everywhere. We aim to become a more inclusive and accepting society, through introducing the meaning of queerness and our culture throughout. 


\section{$\underline{\text { 3. Methodology }}$}

With the foundational ideas surrounding queer theory, communication, and how we exist as a public, I looked to the community and queer culture surrounding me and saw that this is where the research must begin. To demonstrate the need for more community participation, queer spaces, and queer culture, I had to immerse myself in the current existence of all three. Learning about the community starts with hearing our voices, learning what makes a space queer and safe to our public, and acknowledging the various identities within our community and their needs. Understanding the functions of our public not only required observing it, but also experiencing it first-hand, and analyzing how it is portrayed through a pop culture discourse analysis. The combination of these three methods would offer the broadest, most diverse insights into our community. Those perspectives, particularly, how members of the community exist and interact in our queer spaces, how my personal experiences shape my understanding of our queer spaces, and how mainstream media shares and portrays our queer culture as an other, something intrinsically different from the "norm".

Together, these methods form a strong understanding of the needs of our community based on how it is currently functioning, and where it can improve its efficiency and accessibility overall. A wellrounded understanding of the LGBTQ + community and its members is what is required to offer a proper, all-encompassing solution to issues various community members are currently facing. As Norman (2013) said in The Design of Everyday Things, "Good designers never start by trying to solve the problem given to them: they start by trying to understand what the real issues are" (Norman, 2013). In order to design a solution for the community, through my research I must look to issues our community may be facing, have a strong foundational understanding of said issues through the lens of members of the community by hearing their voices and experiencing their spaces. This is the beginning of the Human-Centered Design process, by which observation leads to ideation, prototyping, and testing (Norman, 2013). Beginning my research through observation and first-hand experience, I am ensuring I will have the strongest possible understanding of the problems facing our community so that I can design the strongest possible solution. 


\section{$\underline{\text { 3.1 Participant Observation }}$}

Participant observation is all about learning about a demographic in action. Sometimes what people say may not reflect how they act, and with a study such as this, experiences and interactions need to be observed first-hand. In an effort to learn about the problems the queer community is experiencing, their barriers, fears, and social interactions, it is important to see the perspectives held by its members through their behaviour, in person. I tried to attend as many different queer spaces and events as possible to ensure a perspective seen from the various identities within our community. Problems a lesbian may be facing in the community, may not also be faced by a transgender individual for example, so it was important to ensure a broad scope for analysis. Attending events where community members gather allowed for a fuller experience and understanding of queer culture and the impact queer spaces have on the community. As stated in Qualitative Research Methods: A Data Collector's Field Guide, "Observing and participating are integral to understanding the breadth and complexities of the human experience" (Mack, Woodson, MacQueen, Guest, \& Namey, 2005).

As I attended a variety of queer spaces and events, I went with the intention to determine the general demographic of people present and how they interacted with others inside those spaces. Due to the wide variety of events and spaces I attended, the interactions which took place varied greatly, but there were common patterns that I was able to distinguish across all. I took note of general attendance and enthusiasm within these spaces, how comfortable people seemed, if they knew others within the spaces, or if they went alone. All of these factors are important in determining who has access to our queer spaces, who was able to access our circulated information, and determining which demographics are missing from those spaces, if any. It is the overall aim of Beyond the Bow to reach all types of queer people regardless of age, ethnicity, religion, etc., for the purpose of circulating information and making our resources more accessible.

The channels I primarily found events through included Google, YoHomo, FaceBook, Meetup, establishments themselves, and person to person. As I would arrive to a queer event, I would first make note of who was hosting it and where I was located in relation to various transit systems. Such insights impact design decisions when offering information to users and their ability to access various spaces. 
Upon entering events, I would address my surroundings, the general look and feel of the spaces, determine how many people occupied the spaces, and if they were alone or in groups. One of my goals was to observe the level of diversity in terms of ethnicity, age, and gender identity. I was able to accurately determine preferred pronouns at many events simply by asking one's preferred pronouns when talking, or by seeing name tags that certain events offered. In addition, I observed how frequently strangers would greet others, introduce themselves, and begin conversations. Another factor I looked at was how frequently people would be on their mobile devices instead of engaging in the events.

\subsection{Pop Culture Discourse Analysis}

Conducting a discourse analysis is a method that studies language and the context in which it exists (Adolphus, n.d.) The topic of discourse was discussed by Neilson and Nørreklit (2009) as follows, "a social practice which constructs social identities, social relations and the knowledge and meaning systems of the social world... [which] both reflects and produces the ideas and assumptions relating to the ways in which personal identities, social relations, and knowledge systems are constituted through social practice" (Neilson \& Nørreklit, 2009). To understand society is to understand the way we communicate and the language we use, and to understand the language we use and the way we communicate, we are able to understand society. Conducting a critical discourse analysis of pop culture allows me to understand how it has both reflected and contributed to our social world. By studying the discussion of queerness in pop culture we can better understand society's stance on queerness and how pop culture has impacted that.

Pop culture exists throughout society, providing a platform for many communities, through the act of queering discussed earlier, it proves to be the queer community's largest method of discourse distribution across the world. Through our community's collection of art and culture we are able to utilize mass media to demonstrate what it means to be queer and share pieces of ourselves with the world and each other. Not only are queer community members able to connect with our culture, they are able to connect with each other through mutual pop culture interests. Finding queer related content online has gotten easier over the past decade as social media has begun the spread and discussion of many 
community related issues. Show-runners, writers, artists, athletes, and more, are held accountable by the mass media users, so the portrayal of queer culture in media has not only expanded, but has become more accurate. This has been the greatest tool for the community in helping spread our culture, what it means to be queer, and messages of love for various identities. We are utilizing pop culture to re-shape society and reflect one which is more accepting and inclusive of diversity.

The representation of the LGBTQ+ community in pop culture has allowed for the growth of our community, greater acceptance of our queerness throughout society, and new perspectives from various identities to be brought to the forefront of our media sources. Analyzing various pop culture accounts on what it means to be queer and how we include our queer culture in society will help us better understand how to continue with positive growth, and to continue representing diversity and the LGBTQ+ community in a variety of ways. I will be specifically looking at LGBTQ+ documentary interviews on how they display our queer culture throughout different societies, religions, and cultures. I will also analyze queerness in sports, music, television, social media, and YouTube. Together these areas of pop culture can demonstrate how the LGBTQ+ movement has evolved, and how we are utilizing them as platforms for our voices. Studying queer discourse in pop culture can provide insight both into how our community is viewed throughout society, and how we can utilize it to normalize our existence.

\section{$\underline{\text { 3.3 Autoethnography }}$}

Through participant observation, experiential learning and self-reflection, I am able to better understand the queer community's social and cultural interactions, their needs, and any problems they may face, to work towards designing a digital solution that meets the needs of all community members. As a researcher it is important for me to demonstrate and acknowledge that I am only one person and others may experience our culture in a variety of ways. It was a conscious decision to use this as a method for my research because my research is value-centered, and it aims to sensitize readers to the true social issues within our community. The aim of autoethnography is for the researcher to have a personalized connection and understanding of the culture in which they are trying to learn more about. It is a way for 
the researcher to empathize and experience the culture of the community they are studying first-hand (Ellis, Adams, \& Bochner, 2010).

Autoethnography as a research method in itself is a disruption against traditional forms of gathering data. "Autoethnography—a method that uses personal experience with a culture and/or a cultural identity to make unfamiliar characteristics of the culture and/or identity familiar for insiders and outsiders" (Adams \& Holman Jones, 2011). To understand the queer community and how to maintain the voices of all identities when discussing the needs of our community with others, I must utilize a research method which allows me to humanize the qualitative data so that others can relate to, and interpret it. This is a personal narrative surrounding my experiences and observations of others.

As I began my research, I did everything in my power to eliminate any pre-existing bias. This first included clearing cookie caches on my computer and online accounts to ensure when I searched for events, information, and resources, I was not being given information previously searched for, or built towards my online profile. For example, as a woman who has previously attended a lesbian event, I wanted to ensure I was not being primarily fed lesbian-specific information, or events specifically for women. The first step in one's journey when taking part in the queer community is finding queer events. I did so through a variety of ways, most often beginning with a simple Google search, "Queer events in Toronto", as most do, or it would be reaching out to friends to inquire if they have heard about any upcoming events they would recommend. It was from this moment, searching for queer spaces, that I considered my journey to have begun. As soon as the first search results popped up, or responses started rolling in from friends, I began reflecting on my journey.

The questions I asked when self-reflecting on my overall experiences included:

1. Was this event or space easy to find, both virtually and physically?

2. Is this my first time attending this event/space and am I frustrated that I have never heard about this event/space previously?

3. Do I feel comfortable attending the event/space?

4. Do I feel safe?

5. Was it accessible to me in terms of transit and cost?

6. Do I feel welcome at/in this event/space? 
7. Am I happy being here?

8. Do I feel like this space accurately reflects the LGBTQ+ community and is diverse and inclusive of all members?

9. Is there anything missing from this space?

10. Do I wish to attend again?

Throughout the events or my time in various queer environments, I would completely immerse myself in what was taking place, constantly taking note of how I was feeling in the space, and simultaneously observing if the general atmosphere reflected similar feelings. Questions such as these were my frequent check-ins with myself and the setting to fully grasp the type of space I was in and how it seemed to be reflecting onto the members attending. Taking note of the general atmosphere of a space really helped determine the level of comfort attendees had. This was important to note when considering anxiety, or other comfort and ultimately accessibility barriers, queer members may be facing when searching for spaces to attend.

Autoethnography required me to constantly think about what I was doing and why I was doing it. What I was feeling and why I was feeling it. Every feeling and thought was the result of something and all of it mattered in order for me to understand the importance and needs of, and for, queer spaces. Society accommodating the needs of the LGBTQ+ community comes from learning those needs directly from its members. Through detailed accounts of queer experiences we can shape spaces, events, and virtual tools to reflect the needs of our community, which have to be met to ensure its success moving into the future. The queer movement, queering spaces, and ensuring the growth of our community starts from listening to members of the community and truly grasping what is essential to our members. 


\section{Results}

As a result of utilizing current channels to find and attend queer events, I discovered several flaws in how information is shared and distributed. Whether it was a buggy app, incorrect information being displayed, or simply not being posted on an establishment's website ahead of time, access to event information was limited and difficult to find. If the first step in trying to get involved with queer culture in society is difficult, many people simply will not. Making access to information easier and more efficient is the first step in addressing accessibility concerns within the community.

Continuing, upon arrival to events, one of my biggest findings were the connections people in the community already had prior to entering an event. This was an important observation in understanding that LGBTQ+ individuals may feel the need to have a connection for safety or comfort prior to attending a queer space. In almost all situations, all people in LGBTQ+ places were accompanied by a friend or with a group of people they had already met. This was true for the concert (Event, Nov. 15, 2018) and film festival (Event, May 28, 2016) I attended, where such events were pre-planned by people wanting to attend with friends and purchase tickets ahead of time. LGBTQ+ events such as the Toronto Gaymers Meetup (Event, July 22, 2019) and Queering the Academy (Event, Nov. 1, 2018) demonstrated more stranger sociability, where many people were meeting for the first time for a shared purpose. Whether it was to play Dungeons and Dragons together or discuss how to incorporate queerness in educational institutions and curriculum, these spaces were meant for a collection of strangers to come together and complete a task.

When an event was open to various identities and had an overall purpose that required collaboration, strangers were much more open to talking and meeting one another. This connection was possible through such events and people did not seem uncomfortable with it at all. Giving strangers a shared purpose in addition to bonding over their queerness, members were very open to interacting with one another. The Toronto Gaymers Meetup was so unique to me because it was one of the most diverse events I attended in terms of ethnicity, age, gender identity, and background.

Separately, I determined that the age and identity distribution was completely dependent on the types of events being run. The comedy nights (Event, July 16, 2019, \& Event, July 23, 2019) were a good 
range of ages from early twenties, to what appeared early fifties, and had a diverse group of identities and ethnicities. The same could be said for the film festival (Event, May 28, 2016), the Toronto Gaymers Meetup (Event, July 22, 2019), Ellen Degeneres' show (Event, March 3, 2019), Rainbow Ski Weekend (Event, March $23 \&$ 24, 2019) and Queering the Academy (Event, Nov. 1, 2018). The events which were restricted to specific identities such as Sapphic Aquatica (Event, July 28, 2019), which did not allow any cisgender men, still had diverse ethnicities, and ages, but was limited to gender non-conforming, women, and transgender identities. Apart from Glad Day (Event, July 10, 2019) and Pride Ski Weekend (Event, March 23 \& 24, 2019), spaces and events were generally geared towards community members nineteen plus. There were children in these spaces, but apart from these I did not observe many individuals under the age of nineteen. I was able to understand the identities and ages which attended various events simply based on the events themselves being meant for specific audiences. During the week, most queer events take place in the evening, thus they are generally intended for an older audience.

Events meant for specific identities can offer safe spaces in which members feel most comfortable, while also meeting others and getting involved with the community. Because events meant for specific identities are not frequently run, or as frequently as the community would hope, those who attend such spaces and events, really have an appreciation for their time there and this can be noticed by how involved and attentive they are. When researching potential events to attend, I came across Sapphic Aquatica (Event, July 28, 2019), and because it was an event limited to specific gender identities, I was curious how often it ran. This specific event is only available for five nights throughout an entire year, and based on the large turnout of people and the positive atmosphere, I could instantly tell it was a special event for many. Also, I was amazed at how disconnected from personal devices, members of the community were while in queer spaces. As a researcher, I read this as an indication of the importance and preciousness associated with queer spaces and the time community members have in them. The only instances I observed where people were consistently grabbing their phones, was to connect with others they had just met in person on social media.

I have made friends through attending queer spaces and immediately connected on social media, but the first several times attending a new space alone can be intimidating. While self-reflecting after attending all of the different queer spaces, I found that comfort was my largest barrier to not attending 
events prior to beginning this study. During the study however, the largest barrier was finding events accessible to me in the first place. Whether that was based on physical locations being inaccessible, or restrictions on events based on age or identity, the experience of getting involved with our community was never completely smooth and I hope through more research and development of new tools, this can change.

As I jump into my personal reflection of queer spaces and events, I would like to once again mention the Toronto Gaymers event (Event, July 22, 2019). When I observed others in this space, I felt as though we shared the same experience. I sat at a table with seven complete strangers and felt perfectly comfortable role-playing a fantasy game that requires a level of confidence to join in the first place. I had played Dungeons and Dragons previously, but I had never been part of a game that incorporated queer themes, had players assuming the identity of queer characters besides my own, or was comprised of a group of queer players. We were able to joke with one another about queer stereotypes in the game, discuss queer experiences in real life, and even talk about personal topics like our careers or where we have travelled. I have never in my life, felt as comfortable and welcomed than I did in that moment with a group of complete strangers gathering over our love of a role-playing games and our queerness, and I honestly believe the same experience can be said for each of them.

Similarly, I attended Pride Toronto three years ago for the very first time, and this was the very first moment where I was surrounded by members of the community like myself. The experience one has surrounded by community members in a completely safe space is why community building and queering spaces is important. The sense of community one experiences while being surrounded by those like themselves is incomparable. During a meeting with a queer spiritual leader (Event, August 1, 2019), we discussed this topic of being fully immersed in queer culture, surrounded by queer people, and how it can be considered a conversion event. It is a eureka moment that exists when you have not only accepted others, but have felt completely loved both by your community and yourself. Just having this conversation with a queer spiritual leader felt like a conversion moment in itself. I felt safe, happy, loved, and welcomed in a space regardless of my identity. To create spaces and events which facilitate such experiences is the overall goal of the queer movement. 
As touched upon previously, addressing comfort as a barrier to accessibility is something I have been exploring with as I attend more queer spaces. From my experience and the queer friends within my social circle, attending a queer space only occurs for the first time when you have a queer friend or ally willing to accompany you. Like doing anything else for the first time, there is a level of anxiety or nervousness associated with it. The same can be said for attending queer spaces or events, but having the added concerns of safety, insecurity with one's own identity, and even questioning if one belongs in such a space.

Furthermore, I have found many queer events to be specific in nature in terms of the demographic welcomed. For example, how old attendees must be, what orientation or gender identity they must have, or others. Also stated earlier, these restrictions can offer both a sense of comfort for attendees within the specified identity or age, knowing they are among community members who can relate to them on the deepest level, but conversely, make all others feel unwelcome or uncomfortable entering those specific spaces. This is a fine balance that needs to be kept through offering events that meet the needs of all community members, whether those be identity-specific spaces, or open to the entirety of the community.

A specific example of this occurred with me joining Meetup groups online. I live in the GTA, not specifically the downtown core, so I was curious about what events were available outside the city. One such group is the thirty-five and over lesbian group in Durham. Unfortunately, it was the only Durham queer group I found and as a fluid woman under thirty-five, felt unable to join. They often held social gatherings meant to discuss individual's experiences with queerness, and they seemed like intimate gatherings meant specifically to offer a safe space for lesbians of that age group. I understand the need for such specific groups and did not feel comfortable joining such safe spaces without being invited. This indicated that both identity-specific and open queer events are necessary to meet the needs of the queer community, and Beyond the Bow will be able to help users filter such events to meet their individual needs. The tool can be used to help users connect and attend the queer events they prefer based on their level of comfort. This is how Beyond the Bow can assist with comfort and accessibility.

Discussing identity specific events, I experienced the Sapphic Aquatica event (Event, July 28, 2019). As I had previously mentioned, this event was not open to cisgender men, and I felt extremely 
comfortable and empowered to be surrounded by other women and gender non-conforming community members. For an event that seemed very intimidating due to the nature of the establishment, I actually felt very comfortable, welcome, and safe. The space in which this event occurs is a known Toronto sex club and they are very clear on their acceptance of various gender identities, sexualities, and body types. There is a no hate policy within the space and having establishments take a very strong, open stance on such matters, not only queers their space, but makes you feel safe and welcome. Attendees of the event were all extremely comfortable, and were open to talking with strangers. I had several conversations with strangers and I observed many new conversations and meetings taking place throughout the night. The space welcomed stranger sociability and provided a safe environment where individuals could express their identities openly.

Continuing on the idea surrounding comfort, and reflecting on my own experiences, I was interested in understanding how I cope with such concerns and creating potential solutions for others. After meeting with the a queer spiritual leader in Toronto (Event, August 1,2019) for the purpose of discussing religious room for queerness through physical spaces and events, and watching a video discussing how queer communities feel welcome within places of their faith, I started thinking about the idea of faith as another avenue to immerse oneself with the queer community. Those who are religious and queer still gather at places of their faith to practice, so offering queer-specific religious events would allow for deeper connections between community members where they also share their faith.

I think the gatherings of spiritual people bear one of the strongest senses of community. You know you are surrounded by those with the same values and desire to make the world a better place through religion or spirituality, and that offers a level of comfort when facing stranger sociability. I also think this has an added layer in the sense of the community one belongs to. Their sense of spiritual connection and knowing they have a community within their faith offers a level of confidence when attending places of worship or spiritual gatherings, and this may help queer members navigate their own identity. Navigating one's faith and identity can sometimes be difficult. Prior to this study I only knew of a few religious spaces which showed solidarity with the queer community, but had I known about such spaces during my own explorations, I confidently believe I would have felt more comfortable with my 
identity. Finding spaces which enhance your sense of community and belonging are those which help you feel welcome and normal.

The biggest pattern I have noticed in queer spaces thus far is the level of comfort people have in order to attend them in the first place. For many in the community who may be uncomfortable putting themselves in a new situation for the first time where they don't know anyone, meeting others in the community through means of their faith and spirituality could be the solution for them. This goes back to the discussion of how we interact with strangers in different publics and communication being the basis of human fellowship. Communicating through shared faith offers an avenue for producing a social bond which can tie strangers together. Spiritual spaces are able to be made queer through showing solidarity with the community by running events, offering spiritual guidance, and even displaying a pride flag in front of a place of worship. These are clear signs which make the LGBTQ+ community feel welcome and safe in a religious space, which in some cases, can be most oppressive of sexuality.

Although spirituality was not the avenue I personally used to become involved with the queer community, I did have a similar avenue into community events where I first attended with purpose, and then made friends and felt comfortable attending them on my own. I know I have such a strong desire to share queer culture and our beautiful community with other members who have not accessed or participate in it yet. The entirety of my participation and involvement within the queer community is responsible for my desire to create tools that make accessing our culture and getting involved easier. Through participating in my community, I have witnessed and understood the needs we have and I realized the importance, and potential we have to create safe spaces and promote the wellbeing of LGBTQ+ people throughout society.

Overall, the common themes I noticed by conducting participant observation were how comfortable people in queer spaces were, how diverse our community is, how appreciative our community members are of all queer spaces available to us, and how we have created these spaces for ourself throughout society. Seeing how happy and comfortable the LGBTQ+ community is in the GTA within our queer spaces is a huge indicator towards the need for more spaces, and an indication that the information we are sharing needs to be available for all members to ensure everyone experiences this culture. 
My analysis of queerness in media, through videos, news, art, and more, led me to determine that society and pop culture's portrayal of discourse is dependent on the language we use and how we assign meaning. When we inaccurately portray the queer community through media and use homophobic language, society starts to reflect those ideas. Vice versa, when we correctly represent diversity and promote inclusion through appropriate language, we are educating society and reshaping it to be one which is more accepting of differences. This is important not only for the general public, but those in the queer community who are still trying to navigate their own identity. Seeing more queerness in pop culture gave me a sense of confidence to openly exist as my true self more publicly, and get involved with queer initiatives to help others feel that way as well. I had suddenly felt a sense of responsibility to help create spaces and a society where every queer person feels comfortable and confident. Pop culture has that ability to empower communities to become involved with a culture that they relate to on a deeper level. Mass distribution of our art, our culture, and our people's work is how we encourage diversity throughout society and acceptance of the LGBTQ+ community.

For many, queerness in pop culture is the first idea or exposure one has to what the LGBTQ+ community is all about. Through analyzing pop culture we can see the historical impact media has had on the queer community, both positively and negatively. From feeling empowered through seeing artists taking a stance and openly supporting the LGBTQ+ community, to media coverage limiting portrayal and actively blocking the spread of queer discourse in a positive light, pop culture is responsible for the largest advances and drawbacks of the queer movement.

To understand how we can support the queer movement and continue painting the LGBTQ+ community in a positive light, I reflected on what events throughout our queer history have done the opposite. I would personally argue the single most devastating drawback in the queer movement was the AIDS epidemic in the 1980 s and how queer men were portrayed in the media. From the specific language media used in describing queer men, to simply not allowing the discussion of homosexuality at all, the queer movement took a hit that has still felt repercussions to this day. When the epidemic hit, gay and bisexual men were banned from donating blood. Just this year in Canada, blood donation regulations changed from a ban of one year after having sex, to three months, and previous to that in 2006 , regulations changed from a complete life ban, to a ban of five years (Larsen, 2019). Such a system was 
the result of incorrect and homophobic portrayal of the gay community in media during the eighties and nineties.

It has been thirty years since the eighties and only now are regulations switching to a fair, evidence-based system for blood donations. This engrained fear was the result of mass distribution of an incorrect, dangerous, homophobic narrative that has impacted our community to this day. The discourse spread through pop culture soon reflected society's view on gay men and a viscous cycle was created. However, through the same tools and channels, we are able to reclaim our own narratives and educate the public on our queerness. With idols such as Ellen Degeneres, Elton John, Lady Gaga, and so many more, queerness has been brought to the forefront of media once again, through the lens of members actually in the community. The correct portrayal of our narratives comes from us, and community members are using their voices, their status, and their accessible channels to help spread messages of love and education with a hope that this will eventually reflect society's view on the LGBTQ+ community.

Megan Rapinoe, two-time world cup soccer champion and olympic gold-medalist, has been open about her lesbian sexuality, and has inspired and empowered teammates, other professional athletes, and young athletes alike, to embrace their own sexuality and live as their true selves. Seeing our athletes, artists, comedians, news anchors, etc., embracing their queerness and living openly, not only spreads positive messages surrounding queerness, it helps educate society to become more accepting of diversity. Queerness in pop culture is responsible for the open discussions surrounding the LGBTQ+ community through social media. LGBTQ+ members have created social media accounts to connect with others in the community and share queer discourse online. Social media accounts like Tumblr, Twitter, and Instagram users, are finding online communities to discuss our representation in pop culture and often times rally against any misrepresentation or mistreatment of queer culture and people online.

A direct instance of pop culture enacting change and creating a physical queer space in society was the mistreatment of queer characters in the TV show The 100. As soon as two character were confirmed to be in a queer relationship, one of them was killed off the show, and this is a repetitive trope known as "Bury Your Gays" (Phillips, 2017). The two characters of the show, Clarke and Lexa, became a symbol of this trope and fans rallied on social media to hold show-runners responsible for using queer characters simply to claim a diverse story. After, rallying fans created an entire queer convention called 
ClexaCon dedicated to demanding proper queer representation. Now, queer women gather every year to a convention that showcases queer characters from movies and shows, and offers a space for networking, learning various skills through workshops, making friends, and learning more about queer art in cinema.

This is a great example of the impact queerness in pop culture has had in enacting real-life, physical change. Not only was a convention created, many fans became friends through their mutual interest in queer characters, and now show-runners and art creators alike are held to a higher standard when it comes to properly and fairly representing queer culture. Utilizing pop culture and social media to spread accurate queer content and representation of our public is exactly what we need to continue growing and thriving as a community. Creating physical events like ClexaCon was possible thanks to the virtual tools our community has utilized, and creating a queer specific virtual tool such as Beyond the Bow has the potential to draw even more queer voices to help create LGBTQ+ spaces in society. We are using pop culture to reflect the accurate discourse of our queer community, in hopes to normalize our existence and culture throughout society.

By fully immersing myself and interacting in a variety of queer environments, I have come to better understand how queer spaces exist and thrive in and around Toronto. I have come to identify where our community can improve in its distribution of information and resources to foster participation of LGBTQ+ members in the community. Immediately upon beginning my research, patterns such as accessibility barriers and the importance of queer spaces to members in the community became evident, and some pre-existing thoughts and assumptions were confirmed. The queer community in Toronto does indeed offer a variety of events throughout the year for various LGBTQ+ identities and the way which information is primarily distributed is through a few specific channels mentioned earlier. Conducting searches was difficult and not one online resource on its own contained all of the information I would need for a specific event. Multiple times I had to hop between two or more websites to determine where an event was taking place, who was hosting it, if I needed to pay an entrance fee or purchase tickets ahead of time, and if there were any specific requirements or restrictions for the event.

This was a barrier not only by adding to the issue of inaccessibility, but I actually ended up not being able to get into and event (Event, July 8, 2019) because I had not purchased tickets after the event page on YoHomo detailed it is as requiring no cover. That led me to assume no entry fee or ticket would 
be required for the event. Right before attending, it was discovered that the FaceBook event created by the hosts themselves included an Eventbrite link for tickets and more instructions. These are small barriers that limit access to queer events which could easily be eliminated by a better functioning virtual system that correctly includes all required information in a simple, easy-to-use way. Conducting this study made it evident that the current virtual tools available to the queer community lack in some manner.

I do believe that our queer spaces and events would look different and be more inclusive, should we have reliable, efficient, and safe channels to distribute our resources an information. I cannot speak on behalf of others, but these tools are universal and I feel everyone can agree that they could be improved. The LGBTQ+ community and its members deserve and need reliable avenues to participate within our public. This is necessary to cultivate the growth and prosperity of our community to ensure all members will one day have access to their queer safe spaces. 


\section{Landscape Analysis}

Conducting a landscape analysis of tools that currently exist for the queer community helped me realize why I wanted to conduct this research and create a better digital tool in the first place. Tools which currently exist in, or for the community, lack in one or multiple of the following departments. a) They are not queer specific, running the risk users feeling unsafe or unsure. This was primarily true for FaceBook users, where often times friends and family can see which events you are attending if your privacy settings are not adjusted accordingly. This was a tool I avoided using specifically for that reason prior to openly identifying as queer. b) They are not completely functioning or partially broken. HER, a women-only dating app which also attempts to connect strangers with events, is often not completely functioning, or the app crashes. c) They do not provide all the information. With the case of YoHomo, or even HER, these virtual tools are missing key event information, or simply not mentioning all of the available events to the queer community in the first place.

These tools all exist for ulterior purposes, whether they work as dating apps or they are not a completely safe queer space. They fall short to meet the needs of our community in accessing our queer culture and keeping us informed of our discourse and information. Because no all-encompassing tool yet exists, spaces such as Glad Day and other queer venues are displaying their event information on their personal websites or store-fronts. For members of the queer community who have not heard about such spaces previously, they would not know how to access such event information. Beyond the Bow would be a tool that businesses utilize to display their events and circulate information regarding their establishment, so that users who may not have heard of them, would then be able to on a single platform. 


\section{Synthesis/Analysis}

The queer community is in need of a modernized form of communication which draws together information regarding events, resources, and culture on one convenient platform. Creating a queer virtual platform for LGBTQ+ members to connect, find resources, and get involved in the queer culture surrounding them, is exactly what our public needs to continue growing and thriving. Beyond the Bow has the ability to be that virtual platform that solves issues of accessibility, promotes representation, and assists users in immersing themselves in the queer community near them. It will offer a variety of features that enhance usability and ensure a smooth experience to empower users in getting involved.

Beyond the Bow will allow users to first create a profile, including any information they wish about themselves such as gender identity, sexuality, age, location, and interests. All features will be able to be kept anonymous to ensure user comfort, especially for those who are still exploring their identities. This helps LGBTQ+ community members who do not wish to label themselves, but for those who do, gives an opportunity for them to meet other users who share some of those profile details with them. This also helps with comfort, where users are looking to meet queer members they can relate to. When I was conducting my study I noticed the only instances where people were grabbing their phones during events, was to connect with others they had just met in person on social media. People want to connect online, so providing a feature for users to connect through the app and share events with each other to attend in the future will help build and strengthen our community.

In addition to connecting with new and old friends through the app, giving the opportunity for users to display such information about themselves will also help them filter events and information based on their preferences if they so choose. Another feature of the app which will help immerse users in a variety of queer culture, is the ability to enact "modes". For example, a middle-aged gay user wants to attended an arts related queer event, but majority of their events page is filled with nightlife. They can specifically filter out all nightlife-related events when they are not in the mood for such. Rather they can specifically filter to events which fit their current needs, mood, wants, etc. Are you looking for something fun for you and your friends to do on a Friday night, or are you hoping for something more educational and relaxed to attend with a family? As I had stated earlier, giving groups of people a task to complete 
within a queer space increases the chances of stranger sociability much more, and knowing others are in the same position as you, interacting with strangers, makes you feel more comfortable. Through the use of modes and filters, users will be able to find events that are activity based which offer this layer of comfort and confidence.

Through my research I have found many queer events to be specific in nature in terms of the demographic welcomed. For example, how old attendees must be, what orientation or gender identity they must have, etc. Creating filter features within the app allows for users to accurately find events that are specific to their sexual orientation or gender identity so that they can save the date and plan ahead to attend. This would be possible through Beyond the Bow, and all users regardless of interest would find purpose and have the desire to utilize this tool and attend queer spaces that suit their needs.

During my study, the largest barrier was finding events accessible to me in the first place. Whether that was based on physical locations being inaccessible, or restrictions on events based on age or identity, the experience of getting involved with our community was never completely smooth. A unique feature of Beyond the Bow will be the ability to view all current spaces and events on a real-time map, where users would not only be able to see what is in their area, but any transportation information such as nearest TTC stations or bus stops. Also, users would be able to upload events and spaces they have heard of or recommend for other community members. This is how we will modernize and utilize the traditional channel of person-to-person information sharing within our public, while also incorporating benefits of mass media sharing. Combining channels the queer community has traditionally utilized, and publishing shared information in an easily accessible way to the entirety of the community is how we not only sustain our public, but help it grow in the face of technology and modernization. We have the ability to keep up with the virtually changing world and cultivate the growth of our queer spaces in the physical. This is how bridging the gap between the virtual and the physical can become possible.

Beyond the Bow's core values are community building, safety, and queering spaces, therefore this tool is meant to facilitate $\mathrm{LGBTQ}+$ member participation in our culture, maintain safety within our community, and continue queering spaces throughout society by partnering to offer queer-specific events. I want to give all LGBTQ+ members a tool that helps them become involved with our community and in turn, facilitate the growth of more spaces within our society. With greater participation, will come growth 
and cultivation of more queer spaces throughout society. Beyond the Bow can help get that ball rolling quicker, and enhance community experience along that way. We want to eliminate frustration regarding access, limitations, and lack of community spaces by offering this digital solution. It will take participation and require user feedback just like everything else, but this is how we can work together as a community to help meet our needs. The community starts with us, and its success is dependent on our involvement and facilitation.

In conclusion, Beyond the Bow users will be able to create a profile based on their identities and filter events, resources, and spaces through the app allowing them to immerse themselves within the community. All users, regardless of their age or identities, will be able to access the information they need and want more efficiently. This convenient app will not only foster participation of queer people in the community, it will also lead to the creation of new queer spaces that will eventually meet the needs of all LGBTQ+ people. This virtual safe space will provide a network of connections and information, that ultimately cultivates community participation in otherwise inaccessible spaces within our overall society. Beyond the Bow is a digital solution for a major societal problem.

\section{$\underline{6.1 \text { Next Steps }}$}

Beyond the Bow needs to go into the design and development phase where interviews of other queer members are to be conducted. A dedicated and diverse team needs to be put together to help make this app come to fruition and ensure it is done so in a way that is representative of all identities. Also, safety is one of the largest concerns in the LGBTQ+ community, and more research needs to be conducted into how we can guarantee the utmost protection for Beyond the Bow users. I would also like to discuss the needs of our younger LGBTQ+ community members and how we can get them more involved with our culture when they often face the most barriers out of all of us. Most often they are still in the closet, have no way to get to a queer specific space, or even meet other queer people their age as they are in the same position as them.

As a young queer woman, I remember being extremely concerned about any online activity or app usage I had for fear my parents or friends would discover my sexuality. I would like to research the 
potential for an incognito mode or similar feature by which users can be on the app and if a parent or friend would ask to see their phone, there would be no indication of what Beyond the Bow's actual purpose is. This has been an idea I have been exploring, but am unsure how possible it actually is. Finding a team of developers who share Beyond the Bow's values is the near future of this project. Researching safety methods, interviewing community members, and developing the app are the next steps for Beyond the Bow and my work. 


\section{$\underline{\text { Appendix }}$}

Queer Events/Spaces I have attended:

1. Inside Out Movie Festival - May 28, 2016

- A queer movie festival that takes place annually in Toronto and Ottawa.

2. Queering the Academy - Nov. 1, 2018

- A campaign run at Trent University with aims to break down cisgenderism/heterosexism in education, and incorporate more queer themes to various aspects of the academic institution.

3. Ria Mae Concert - Nov. 15, 2018

- A queer Canadian singer hosted a Canadian tour.

4. A Conversation with Ellen Degeneres Show - March 3, 2019

- Ellen Degeneres taking part in a hour-long, live interview discussing various experiences throughout her life, including many related to her queer journey.

5. Rainbow Ski Weekend - March 23 and 24, 2019

- An LGBTQ+ celebration of winter pride at Blue Mountain.

6. Science is a Drag - July 8, 2019

- Scientists challenge cis/heteronormative stereotypes of science through live interactive experiments in drag.

7. 519 meditation/feel sexy - July 82019

- An introduction to heels dance class followed by a guided meditation at the 519 queer community center.

8. GLAD DAY - July 10, 2019 
- The oldest queer bookstore in the world, where community members gather, socialize, read, and have food and drinks.

9. Garage Bar - after work drinks - July 10, 2019

- A gay bar in Toronto's gay village.

10. Bi-pandemonium - bisexual comedians - July 16, 2019

- Showcase of some of the city's bisexual, pansexual and sexually fluid comics.

11. Toronto Gaymers D\&D night - July 22, 2019

- A gathering of queer gamers to play Dungeons and Dragons.

12. Gender Outlaws - trans, non-binary, gender non-conforming comedians - July 23, 2019

- Showcase of some of Toronto's transgender, non-binary, and gender nonconforming comedians.

13. Sapphic Aquatica: Spa and Social for Women and Trans Folx - July 28, 2019

- Celebration of sex, kink and body positivity through an exclusive event for women and trans folx.

14. Meeting with Queer Spiritual Leader - August 1, 2019

- Discussing spirituality and religion in the lives of LGBTQ+ members. 


\section{$\underline{\text { References }}$}

Adams, T. and Holman Jones, S. (2011). Telling Stories: Reflexivity, Queer Theory, and Autoethnography. Cultural Studies $\leftrightarrow$ Critical Methodologies, 11(2), pp.108-116.

Adolphus, M. (n.d.). How to... use discourse analysis. [online] Labs.emeraldinsight.com. Available at: http://labs.emeraldinsight.com/research/guides/methods/discourse_analysis.htm.

Butler, J. (1988). Performative Acts and Gender Constitution: An Essay in Phenomenology and Feminist Theory. Theatre Journal,40(4), 519-531. doi:10.2307/3207893

Butler, J. (1990). Gender trouble: Feminism and the subversion of identity. New York: Routledge.

Butler, J. (1993). Critically Queer. GLQ: A Journal of Lesbian and Gay Studies, 1(1), pp.17-32.

[BuzzFeedVideo]. (2017, April 27). Why Prom Should Be For Everyone • BuzzFeed's Queer Prom [Video File]. Retrieved from https://youtu.be/4vpiyRIU2cE

Carey, J. (1989). "A Cultural Approach to Communication." Communication as Culture: Essays on Media and Society. Boston: Unwin Hyman.

Denzin, N. K., \& Lincoln, Y. S. (2005). The SAGE handbook of qualitative research. Thousand Oaks: Sage Publications.

Ellis, C., Adams, T. E., \& Bochner, A. P. (2010). Autoethnography: An Overview [40 paragraphs]. Forum Qualitative Sozialforschung / Forum: Qualitative Social Research, 12(1), Art. 10, http://nbnresolving.de/urn:nbn:de:0114-fqs1101108.

Hansen, M. (2004). Room-for-Play: Benjamin's Gamble with Cinema. October, 109, 3-45. Retrieved from http://www.jstor.org/stable/3397658

Hillock, S. and Mulé, N. (2017). Queering Social Work Education. Vancouver: UBC Press.

Larsen, K. (2019). Blood-donation deferral period drops to 3 months for gay, bisexual men. [online] CBC. Available at: https://www.cbc.ca/news/canada/british-columbia/gay-bisexual-men-blooddonation-deferral-period-1.5127608. 
Mack, N., Woodsong, C., MacQueen, K., Guest, G. and Namey, E. (2005) Qualitative Research Methods: A Data Collector's Field Guide. Family Health International (FHI), USA.

Molloy, P. (2019). 'Go gays!': Why USA's LGBTQ World Cup stars are more important than ever. [online] The Guardian. Available at: https://www.theguardian.com/football/2019/jul/05/usa-gay-playerswomens-world-cup-megan-rapinoe.

Nielson, A.E. and Nørreklit, H. (2009), "A discourse analysis of the disciplinary power of management coaching", Society and Business Review, Vol. 4 No. 3, pp. 202-214.

Norman, D. A. (2013). The Design of Everyday Things (Revised and expanded edition). New York: Basic Books.

Phillips, A. (2017). 62 Lesbian \& Bisexual Female Characters Killed Over Past Two Television Seasons. [online] Out.com. Available at: https://www.out.com/news-opinion/2017/7/11/62-lesbian-bisexualfemale-characters-killed-over-past-two-television-seasons.

UnsolicitedProject (n.d.). Home [YouTube Channel]. Retrieved from https://www.youtube.com/user/ UnsolicitedProject

Vice. (2016, March 2). Gaycation. Retrieved from https://www.viceland.com/en_us/show/gaycation

Villarreal, D. (2019). World Cup final features the 2 most LGBTQ teams. [online] Outsports. Available at: https://www.outsports.com/2019/7/5/20683450/us-netherlands-lesbian-bisexual-soccerplayers-2019-fifa-womens-world-cup.

Warner, M. (2002). Publics and Counterpublics. Public Culture 14(1), 49-90. Duke University Press. Retrieved from Project MUSE database. 